\title{
PANDORA: MITO E ICONO PARA UNA FIESTA REAL
}

Enrica Cancelliere Dipartimento di Letterature e culture europee (DILCE) Facoltà di Lettere e Filosofia Università degli Studi di Palermo Via delle Scienze. Edificio 12 90128 Palermo. Italia enricacancelliere@libero.it

[Anuario calderoniano (ISSN: 1888-8046), 3, 2010, pp. 67-85]

El mito de Pandora, uno de los más esotéricos del mundo clásico, tras repetidas revisitaciones helenísticas, medievales, renacentistas, renació en época barroca como mito portante de la fiesta teatral por una serie de motivos que atañen a las posibles interpretaciones simbólicas de los contenidos y a las valencias escénicas y espectaculares de su diégesis ${ }^{1}$. Sin duda la versión más compleja es la de Calderón de la Barca en La Estatua de Prometeo 1670, que tiene en cuenta, a través de ingeniosos sincretismos, las diferentes tradiciones: la que asimila Pandora al mito demiúrgico de Pigmalión y de su estatua Galatea

\footnotetext{
${ }^{1}$ Ver Neumeister, 2000, pp. 73-102.
} 
(o Afrodita o lo que sea); la de la creación de la primera mujer, fuente de todo mal con el auxilio de dioses vengativos (versión paralela a la bíblica de la creación de la primera mujer, Eva); la de la divina joven generada por los dioses y dotada de todo bien para la redención de la humanidad; hasta la oscura ciclicidad entre Eros y Tanatos de los rituales arcaicos, por una parte, y por otra, hasta las interpretaciones misteriosóficas y doctrinales de los neoplatónicos y de los teólogos cristianos.

Además, el sincretismo calderoniano cristaliza en una trama original que se sirve de toda esa materia tanto con finalidad celebrativa y edificante, cuanto con una especificidad escénica que en la visión, y sobre todo en la visión-interpretación del icono, encuentra su mayor motivo de fascinación.

De 1676 son las Metamorphoses d'Ovide en rondeaux de Isaac de Benserade, donde el rondeau dedicado a Pandora constituye un enriquecimiento de la obra ovidiana, tributo a la importancia del mito en la cultura clásica. El rondeau era una versión cantilenante con cadencia reiterada destinada a sostener la representación musicada y bailada, como tantas veces le había acaecido al libretista para las fiestas del Rey Sol, con músicas y coreografias de Lulli, según una fórmula del todo análoga a las representaciones del Buen Retiro, realizadas gracias a la colaboración de Juan Hidalgo y Calderón ${ }^{2}$. La Pandora de Benserade, excepcionalmente bella y esposa de Prometeo, consiente que Epimeteo, hermano del esposo, abra la urna. La tradición es la hesíodea de lo femenino como fuente de todo mal para una humanidad antes feliz; por otro lado el episodio bíblico de Adán y Eva se retiene por lo general similar a esta tradición en el ámbito de un contexto aceptable para la cultura hebreo-cristiana.

El poeta francés se refiere al relato que hace Hesíodo en Los trabajos y los días (vv. 57-101) según el cual Pandora - la primera mujer creada - sería una criatura mortal, a pesar de haber sido generada con la intervención de Efesto, versión en la que resulta explícito el tema del mal que proviene del elemento femenino.

Sin embargo las varias tradiciones se contaminan a menudo entre ellas, tanto que, incluso en la versión «filosófica» de Calderón, Pandora está dotada de una maléfica urna dorada. Aun no rehuyendo los mo-

\footnotetext{
${ }^{2}$ Ver Sage, 1970, pp. 37-52.
} 
tivos del Eros, como atributos de la feminidad primigenia, bastante más complejos son los motivos que entretejen La estatua de Prometeo como gran metáfora de metáforas.

Intentemos ahora seguir las etapas de la complejidad calderoniana, procediendo a la vez a un reconocimiento de esas fuentes que posiblemente el autor ha podido manipular en aras de sus objetivos escénicos, celebrativos y sapienciales.

Por lo que se refiere al mito titánico de Prometeo, Calderón probablemente lo conocía gracias a la Teogonía de Hesíodo, a la tragedia Prometeo encadenado, la única que nos ha llegado de la trilogía de Esquilo, y a las Etimologías de Isidoro de Sevilla. De todas formas el célebre mito prometeico del robo del fuego, variamente reelaborado y alegorizado en la Europa humanista y renacentista, se asimila en el texto de Calderón a otro mito, precisamente el de Pandora, obra viviente de la acción demiúrgica atribuida al titán rebelde.

Esta versión procede del mitógrafo del siglo VI Fulgencio, quizá el obispo de Ruspe, que, dedicado a la lucha contra el arrianismo de los vándalos, quería eliminar cualquier sospecha de orden divino en Pandora, y declaró la estatua obra del ingenio del mortal Prometeo. No obstante, los dioses infundieron el hálito de la vida en la admirable imagen, de modo que nació la mujer, que, de allí en adelante, fue el revistimiento terreno más bello del alma. Así, la interpretación cristiana y platonizante del mitógrafo relaciona a Pandora con la «primera mujer», Eva, según la tradición bíblica, y con la manifestación material y visible del eidos, que es el alma.

Por tanto, en nuestra opinión, en La estatua de Prometeo el centro del interés y del argumento no resultaría ser la empresa más famosa del héroe —el robo del fuego y su misión civilizadora-, sino la estatua de Pandora, y las consecuencias que para la humanidad derivan de su prodigiosa animación.

Estamos, pues, de acuerdo en plantear que la fuente primaria de Calderón es Boccaccio, - Genealogia deorum gentilium - y la interpretación que de esta misma fuente desarrolló Pérez de Moya en su Filosofía secreta (Madrid, 1585). Otra fuente son los relatos mitográficos de Baltasar de Victoria en su Teatro de los dioses de la gentilidad (Salamanca, 1620-1623).

De hecho las finalidades alegórico-filosóficas de La estatua de Prometeo acogen la versión de Boccaccio, que es además la visión ale- 
górica medieval y, desde Fulgencio, de la joven como «omnium munus»; así como el papel demiúrgico de Prometeo, que con su atrevimiento logra incluso infundir en su estatua un soplo divino. Pero Boccaccio y Pérez de Moya, coincidiendo sobre el hermafroditismo de Pandora, desempeñan por necesidad, a partir del modelo del Simposio platónico, funciones simbólicas bien diferentes de las del texto de Calderón, quien, en cambio, insiste sobre la feminidad de su protagonista, definida por su excepcional hermosura, pero sobre todo so$\mathrm{b}$ re su originaria naturaleza de obra artística, estatua, como es ya evidente desde la elección del título mismo. Así pues las funciones simbólicas calderonianas se fundan todas en las prodigiosas prerrogativas de un icono tan perfecto como para cobrar vida y animarse.

Por más que Calderón se mantenga distante de la erótica universal que los neoplatónicos desarrollaron acerca de este mito, es innegable que las posibilidades de trascendencia - del dato terreno al eidético - justificadas por la excepcional calidad de la estatua, y además por su existencia real en una vitalidad a la vez material y divina, procedan de esas interpretaciones.

La valorización filosófica del mito de Pandora de hecho se verificó al amparo del neoplatonismo, por la función que esta doctrina atribuye a la «materia formada» — por icono o criatura que sea- como impronta que suscita la aspiración a alcanzar la contemplación del eidos, gracias a una ascensión, impulsada por la anámnesis, de los escalones del Eros. Proclo y Olimpiodoro concuerdan pues con Plotino en la versión de Prometeo demiurgo, aunque sostenido por los dioses.

En la concepción plotiniana —que apreciará y de la que se servirá Goethe- es la forma lo que da belleza e ilumina la materia, así que la «materia formada» - Pandora- participa de la belleza cósmica y condensa todos los divinos atributos en una imagen concreta. Así, entre los dones de todos los dioses, son los dones de Venus los fundamentales, porque confieren a la nueva criatura las señas tangibles de una erótica universal.

Es ésta la interpretación metafisica del mito que llega a Marsilio Ficino (Basilea, 1576) y a los demás platónicos de la Academia Florentina, según los cuales el Eros terrenal manifiesta los dones divinos inteligibles y la posibilidad de ascensión. Hija de esta Academia es la elaboración musical y sapiencial de la Camarata de' Bardi de la cual 
es heredera la música de la "fiesta palaciega» calderoniana, de Juan Hidalgo (discípulo del cardenal Rospigliosi), o cuanto menos de su inspiración y estructura, fundada en el estilo recitativo articulado por el verso poético y por su sentido, y en un estilo arioso de gran efecto dramático ${ }^{3}$.

La jornada primera de la Fiesta se abre con Prometeo que llama a voces a los suyos, habitantes de los valles profundos y de las altas cimas de uns Cáucaso fantástico, localización mítica de la cuna de la humanidad, según tradición tanto pagana como bíblica. Luego el héroe invita a todos a acudir al sitio donde pueden admirar su obra y tributarle música, cantos y ofrendas, o sea la efigie de una joven que durante la laboriosa elaboración ha tenido escondida en el fondo de una inaccesible gruta que es asilo de sus estudios y de sus esotéricos experimentos.

Así, con un signo en abismo - semejante a las inscripciones prehistóricas de los graffiti de Venus en las entrañas de la tierra- se inaugura una fiesta musical, cantada y bailada que desde el principio dispone en secuencia los elementos simbólicos de la generación femenina: la gruta, la estatua de la joven en su fondo, y en fin la caja entre sus manos cuando se la donará Discordia.

Prometeo declara haber realizado el laborioso prodigio inspirado por todas las ciencias intelectivas y naturales que se aúnan en la Filosofia, pero incluso gracias a cuanto «... dictaba / el arte de la es-

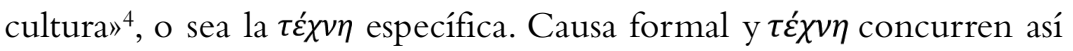
necesariamente en una obra de arte, por ende forjada a imagen y semejanza de Minerva - la diosa que siempre ha acompañado al héroe en sus meditaciones- y asume así el rango de imagen destinada al culto y ritual, objeto de veneración tanto por su belleza cuanto por su finalidad.

Ya otras veces la fiesta barroca calderoniana había encontrado su perno en una estatua, un objeto tan verosímil y perfecto que como sucederá aquí, cobra vida, por ejemplo en La fiera, el rayo y la piedra:

A partire da questo simulacro che si erge come Significante assoluto al centro della scena, è possibile intraprendere la salita ai cieli, cioè il cam-

\footnotetext{
${ }^{3}$ Ver Amadei-Pulice, 1982, pp. 215-230; y Greer, 1986, pp. 122-123.

${ }^{4}$ Calderón de la Barca, La estatua de Prometeo, p. 2070.
} 
mino della conoscenza che si esercita sui diversi gradini dell'Eros, così come vuole l'elaborazione platonizzante di provenienza italiana e rinascimentale ${ }^{5}$.

Pero aquí el icono parece elegido como protagonista, aun inerte y muda durante más de la mitad de la representación, y por consiguiente toda la fiesta parece preguntarse sobre la resolución del enigma de su estatus, motor inmóvil, entre filosofia, estética y religión bajo el disfraz del recurso a la mitología pagana.

Inmediatamente, ya con las primeras palabras a voz en grito de Prometeo, se plantea el importante problema doctrinal, de cómo se puede venerar a un ídolo; o sea, tributar admiración estética que se transforma en culto ritual hacia una obra humana material, inanimada, caduca.

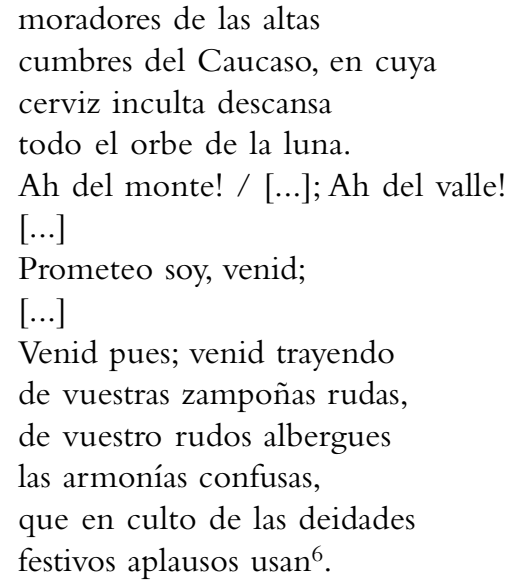

Otro problema será el de justificar cómo tal obra, por lo demás reproducción de una joven de aspecto seductor, pretenda ser viva y estar dotada de alma, precisamente en virtud de su excelente realización, que en todo caso habrá que considerar imperfecta con respecto a la obra del Demiurgo supremo.

\footnotetext{
${ }^{5}$ Cancelliere, 1984, p. 300.

${ }^{6}$ Calderón de la Barca, La estatua de Prometeo, p. 2067.
} 
El hecho es que para Calderón recurrir al icono como motor diegético del plot dramático y como eficaz práctica escenográfica ostensiva y celebrativa se basa en motivos filosóficos y teológicos. Al usar el icono para los fines celebrativos de la «fiesta palaciega» non le escapa al autor que ya en Platón, prescindiendo de los procedimientos mimeticos, el demiurgo, el artífice, intenta con su arte privar a la «forma» de su autorreferencia, de suya a-seidad puramente inteligible, para duplicarla en la realidad espacio-temporal sensitiva.

Por lo demás, el artífice, con esta operación — que Aristóteles precisará estar soportada por técnicas específicas- no hace sino duplicar lo que todo el mundo sensitivo, el mundo natural, efectúa respecto al Eidos hiperuranio, y por consiguiente no hace más que revelar y poner de manifiesto el procedimento mismo de la duplicación. De ello resulta, siempre con Platón, que: «cualquier cosa, pues, de la que el demiurgo realice la forma y la potencia mirando a lo que se mantiene siempre idéntico a sí mismo y sirviéndose de eso como modelo, resulta por necesidad totalmente bella ${ }^{7}$.

De esto la flagrante belleza del icono a la vez que su valor sapiencial, como elementos básicos de la praxis escénica e icónica calderoniana.

Para Platón la práctica del doble dotada de semejanza es pues connatural a la producción de la imagen, la cual es de por sí «semejanza» $($ омонк). Sin embargo ello presupone que lo real, el dato sensible, sea ya dúplice al menos en cuanto a su forma, la cual se conforma a una alteridad que es sólo inteligible. De ahí se infiere que el trabajo de duplicación del artista es experiencia cognoscitiva por la cual la historia de las imágenes y sus recíprocas interferencias se aclaran en sus conexiones formales, y es al mismo tiempo experiencia mística e intelectual soportada por la anámnesis, recuerdo y aspiración al Eidos.

De hecho fueron éstas las presuposiciones en que se fundó el análisis del icono entre los neoplatónicos y sobre todo la exégesis de los teólogos cristianos más afines a la formación de nuestro poeta. Para ellos toda interpretación negativa, de ascendencia platónica, acerca del valor de la duplicación del Eidos en la imagen se ve superada por el acto mismo de Dios que, aun siendo creador increado, se encarna en

\footnotetext{
7 Platone, Timeo, 1994, 28a-b.
} 
el Hijo, el dato sensible. Manifestándose así, la invisible divinidad ha dado lugar a la infinita reproducción sensible de si misma ${ }^{8}$.

El trabajo exegético de Gregorio Magno, Giovanni Damasceno, Fulgencio y otros doctos, ha revaluado lo visible en su formal articulación lógico-racional hasta llegar a la fórmula -ipsa pictura quasi scriptura-, y ha planteado el sentido profundo del icono más allá de sus específicos valore formales, y sin embargo, inalcanzable si se prescinde de ellos Esta elaboración doctrinaria es la que acogió el Segundo Concilio de Nicea del 787 d.C. decretando el triunfo de la Iglesia sobre los iconoclastas 9 .

Según el magisterio del Concilio el icono es el paradigma de la imagen, por el hecho de que, siendo «semajanza disímil», se propone como mediación entre lo visible y lo invisible con finalidad cognoscitiva. La imagen mantiene las siguientes correlaciones con su mode-

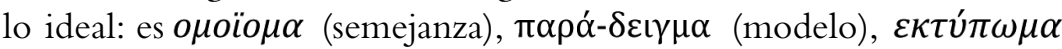

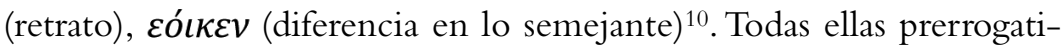
vas que tenemos que reconocerle a nuestra Pandora, imagen perfecta de Minerva obtenida, dice el artífice Prometeo, con todas la cualidades cromáticas, materiales y sensoriales que la naturalezza ofrece y las perfectas formas conmensurables de las ciencias exactas.

Así pues, Calderón utilizó figuras y acontecimientos de la mitología pagana como alegoría de una concepción — la del icono- filtrada a través de la doctrina de la Iglesia a partir de sus raíces en la filosofia helenística.

De esta acreditada formulación doctrinal deriva además que para Calderón la imagen posee valor narrativo, puesto que cuenta en la síntesis de la visión el entero acontecimiento que representa; valor educativo, ya que sustituye las Sagradas Escrituras con funciones cognoscitivas equivalentes; valor simbólico, puesto que su interpretación supera lo que efectivamente muestra; (principio sancionado en Nicea y acogido y reelaborado hoy por los iconólogos di Warburg); valor estético, porque sólo la venustas otorga a la imagen misma esa disposicián formal que consiente al fruidor transcender a la forma pura, inteligible, pues al valor simbólico.

\footnotetext{
${ }^{8}$ Gambino, 2008, p. 136.

${ }^{9}$ Di Giacomo, 1997, pp. 71-86.

${ }^{10}$ Gambino, 2008, p. 129.
} 
La venustas - reconocida como valor por la Iglesia de Occidente a pesar de su origen pagano- implica que la imagen pueda ser objeto de veneratio por parte de los fieles: éstos reservarán al Señor la adoratio, pero la podrán alcanzar a través de la veneratio de las imágenes, cuya disposición se aplica a los datos sensoriales y genera contenidos emocionales.

El Concilio Tridentino aprueba todas las conclusiones de Nicea sobre el valor de las imágines, y además subraya la complejidad de los significados estratificados por la Historia, la importancia de la belleza y el método de análisis de la investigación estética considerada equivalente a la retórica.

El aristotelismo neo-escolástico encuentra ahora una feliz síntesis con la tradición platónica y neoplatónica, así que a partir del Concilio Tridentino la visión mística de las imágenes que informó de sí la teología cristiana y el neoplatonismo, se relaciona con la discursividad y la articulación lógica de una retórica de ascendencia neoaristotélica ${ }^{11}$.

De tal sintesis la dramaturgia de Calderón se hace cargo: el icono calderoniano, según las palabras de Prometeo, está dotado de aquella venustas que solicita, a quien la mira, una interpretación místico-sapiencial que se relaciona al Eidos, y al mismo tiempo es el icono síntesis visible de aquella dicursividad retórica y de aquella articulación lógica - y de hecho Pandora será el símbolo de las Artes y de las Ciencias - que lo hacen lo concreto visible de la metáfora, o sea la quintaesencia del Barroco poético y escénico. Panofsky, hacia la conclusión de su examen en clave iconológica entre fuentes literarias, icónicas, teatrales, afirma:

Pandora se convierte en «manifestación». Como diría Tomaso de Aquino, de un concepto abstracto y filosófico. Esta novedad la introdujo por primera vez Calderón en La estatua de Prometeo, una de aquellas «fiestas» en las que se combinaban entre sí de forma original el entremés manierista, la opera barroca y la comedia bucólica, representadas en el teatro del Buen Retiro por Felipe IV ${ }^{12}$.

\footnotetext{
${ }^{11}$ Di Giacomo, 1997, pp. 71-86.

12 Panofsky, 1992, p. 122.
} 
Esta metáfora icónica calderoniana, representando el dato concreto y visible de un conjunto de doctrinas y teorías filosóficas, construye el significado profundo del texto.

Y así es como en virtud de su concreto valor metafórico la obra, la estatua, anhela a la vida. Calderón, balanceándose entre perversiones, sustracciones y acúmulo de los sentidos; primero opone la visión de la obra al lenguaje, e inmediatamente después pretende que lo que es visible, la obra misma, regenere el lenguaje y con un más alto valor sapiencial, a través de una preciosa estrategia de inversiones sensoriales propias de la estética de la época. Dice Prometeo disponiéndose a concluir la descripción de su trabajo a la muchedumbre:

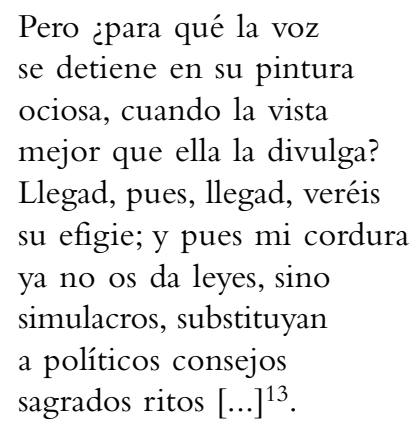

Es oportuno a este propósito recordar que en la sala conciliar de Nicea un altar exhibía las Sagradas Escrituras en frente de otro altar que exhibía el icono de Cristo, y ambos estaban destinados a ilustrarse las unas al otro y viceversa sirviédose de sentidos diferentes, el oído y la vista, con el fin de ascender al común núcleo eidético.

Pero el doble y contrario de Prometeo, el hermano Epimeteo, herido de súbito por la flecha del Amor a la vista por la estatua y a la vez sordamente envidioso, replica:

Prometeo, que tu ingenio es grande nadie lo duda, y cuando alguien lo negara, retóricamente muda

le desmintiera esa estatua,

13 Calderón de la Barca, La estatua de Prometeo, p. 2070. 
puesto que a todos perturba verla algo menos que viva con algo más que defunta ${ }^{14}$.

Atribuyendo con ello a la vista la percepción táctil de la ausencia de respiro y de calor vital, y la auditiva del silencio, la ausencia del lenguaje percibida como condición trágica, falta que señala su inercia corpórea y la muerte.

En tanto, en el arco de la jornada primera un retornelo coral insistente delimita en torno al prodigio en acto el espacio del Cosmos - aquel mismo Cosmos que precipita en la Corte, en la fiesta, en el teatro- e invita al canto y a las danzas, corteses-villanescas y al mismo tiempo alegóricamente rituales: «El monte, el valle, el llano a la espesura» ${ }^{15}$.

Así, en torno al «axis mundi» recobrado, la estatua, la música (evocada en cada estribillo) retorna desplegándose en una estructura en eco que es un preciso código de la modalidad madrigalista barroca, que evoca, para el disfrute y vértigo del oído, la medida de un espacio y de un tiempo cíclicos; espacio y tiempo que se regeneran retornando sobre sí mismos y que miden lo que se pierde y la aspiración al retorno. Es probable que en el frecuente recurso a tales retornelos, que se deducen por las repeticiones del texto verbal, el compositor de la música se haya inspirado en una vena folclórica y popular, pero ello no excluye ingredientes simbolico-filosóficos como descendientes de la Camarata de' Bardi, la cual privilegia la sencillez monódica, precisamente por su enraizamiento en el popularismo mediterráneo, heredero de lo clásico: recuérdense los espléndidos retornelos partenopeos ya en el Aminta de Torquato Tasso.

De nuevo la música en eco se apropia de la simbología cíclica cuando al final de la Jornada I Apolo atraviesa en su carro de oro llameante toda la escena inundándola de su esplendor entonando un canto repetido por la Musica ${ }^{16}$ :

\footnotetext{
14 Calderón de la Barca, La estatua de Prometeo, p. 2070.

15 Amadei-Pulice, 1990.

16 Ver Greer y Stein, 1986.
} 
Apolo Que nazca para morir...

Música Tú mueres para nacer ${ }^{17}$

El retornelo se repite hasta el final de la Jornada, mientras Prometeo - incitado por Minerva la cual quiere que el simulacro de sí misma se anime - le roba al dios, con sacrílego atrevimiento, un rayo de sol con el que infundirá la vida a Pandora, simulacro divino y a la vez criatura viviente que renacerá como símbolo de la eterna generación recíproca de la vida y de la muerte, que mediante las Artes y las Ciencias se cumple en la vida de la humanidad.

La correlación entre Pandora y Minerva le viene a Calderón de

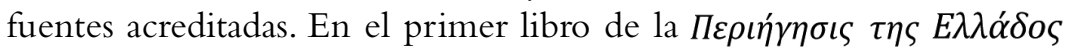
de Pausanias se narra el nacimiento de Pandora representada en el bajorrelieve de Fidias, colocado a la base de la célebre estatua de AtenasPartenos. Además, la descripción que del mismo bajorrelieve brinda Plinio el Viejo en su Naturalis Historia (XXXVI, 18) nos informa de que a aquel nacimiento asistieron veinte divinidades del Olimpo, enriqueciendo a la doncella con sus propios dones.

La relación entre la gigantesca obra crisoelefantina de la Atenea de Fidias y la representación del nacimiento de Pandora ofrecieron el pretexto a Calderón para establecer una sapiencial correspondencia entre las dos divinidades, haciendo de la doncella la imagen misma de Minerva. Por lo demás, lo que Atenas donó a la recién nacida Pandora según esas fuentes se refiere a la cualidad del intelecto, que la diosa misma preside, y de ahí la predisposición a las Artes y a las Ciencias que la fiesta calderoniana celebra como dotes propias de la divina doncella.

Entre la primera y la segunda jornada se desarrollan entanto, entre los dioses y los hombres dos discrepancias paralelas, fruto de dos paralelas duplicaciones.

Calderón con mucho esmero aclara que Palas y Minerva solo en apariencia son la misma diosa: en realidad se trata de dos divinidades gemelas, igualmente bellas y poderosas, pero en eterna lucha entre sí. Mientras Minerva, protectora de Prometeo, preside las Artes y las Ciencias y, en suma, todas las facultades del intelecto, Palas, inspirado-

17 Calderón de la Barca, La estatua de Prometeo, pp. 2076-2077. 
ra de Epimeteo, preside las acvtividades bélicas y venatorias que exaltan en los hombres la "pietas» religiosa y ese viril coraje que los aleja de las comodidades y de la corrupción a que les empujan la ocupación con las Artes y el culto del Saber.

Paralelamente Prometeo es el prototipo del hombre sabio, y por esto artífice y legislador, mientras que Epimeteo, su hermano gemelo, es el prototipo del guerrero, el impulsivo y pasional despreciador de la razón. De aquí la sorda contraposición que lo mueve contra el hermano a partir de la visión del preciado simulacro, y de aquí el furibundo enamoramiento que le invade cuando éste cobra vida, hasta el punto de arrastrarlo a una insensata guerrra civil: la guerra del militarismo totalitario y destructivo contra el buen gobierno iluminado por la sabiduría y por la cultura.

Privilegiando como eje central de interpretación este altercado, de todas maneras se llega a identificar al protagonista, el héroe Prometeo, con la propensión intelectual de su mismo autor; y añadamos nosotros, con el auspicio de que a esta tipología se ajuste el buen gobierno real. Una vez más se subrayan las cualidades culturales e intelectuales que distinguen al hombre del bruto, cuando Prometeo dice: «Este anhelo del saber / que es el que al hombre ilustra / más que otro alguno".

En su exégesis Panofsky llega a subrayar el rasgo de Ilustración antelitteram manifestado por Calderón, una posición que estimuló la revisitación en clave «filsófica» que Voltaire llevó a cabo en su Pandore (1740), opera-comique musicada por Jean Benjamine de La Borde (1765), en la cual se valoriza el alcance simbólico del acto demiúrgico realizado por Prometeo ${ }^{18}$. De todas formas, la obra desarrolla en particular las consecuencias del amor conectándolas con el tema de lo eterno femenino, ya presente en Benserade.

A nuestro parecer un análisis más profundo de Calderón debe sobre todo captar el significado de la serie de duplicaciones que estructuran la fiesta según articulaciones formales que constituyen el verdadero contenido consistente en una profunda hermenéutica del icono. De hecho ya hemos visto lo connaturado que en la interpretación del icono resulta constitutivo el análisis de su duplicidad, filosófica y teológicamente reconocida como tal.

18 Panofsky, 1992, pp. 124-125. 
Esta hermenéutica aclara en el plano del relato y de lo visible escénico todo lo que aquí hemos recordado entre mito, investigación neoplatónica, teología del icono y análisis neoescolástico del motivo iconológico en sí.

El mito de Pandora, como lo asume Calderón, se articula ya de por sí alrededor de las duplicaciones que definen el icono: su naturaleza terrenal y la estructura formal que de todas formas duplica todo dato sensible correlacionándolo a lo supra-sensorial; la duplicación de esta primaria duplicación platónica que lleva a cabo todo demiurgo, y también quien contemple la obra, tanto que anhele al «eidos» pagano o cuanto a lo "divino» cristiano; y por lo tanto la naturaleza doble de la misma Pandora ya en el significado del mito, a la vez estatua y criatura viviente, y a la vez doncella mortal y diosa.

Más allá de la ocasión celebrativa, éste es el núcleo que motivó al poeta, tanto en la articulación diegética cuanto en su manifestación visual, y le indujo a una serie de duplicaciones que instauran una verdadera y propia laberíntica poética del doble, pero se trata de un laberinto sapiencial.

Epimeteo es el doble y el otro de Prometeo y viceversa; Palas el doble y el otro de Minerva; Minerva el doble y el otro de Pandora, tanto que a los dos personajes los interpretaba la misma actriz, que recitaba las partes de ambas sin cambiar de traje ni de posición escénica; aún Minerva, que, con el fin de revelarse a Prometeo se duplica en una fiera simbólica, una serpiente escondida al fondo de una caverna, y de este disfraz se libera cuando quiere manifestar su voluntad; Pandora misma, doble y otro de su simulacro. Este juego de espejos refleja lo «semejante en lo disímil» en sus propios reflejos y a través de ellos se regenera. De este laberinto que traza las vías de una ciclicidad cósmica, solo Goethe - en recuerdo de su Calderón tan querido - supo captar el aspecto desengañado dirigiéndolo hasta el extremo de una melancólica nostalgia existencial gracias a la visión neoplatónica del Eros que infunde en su Pandora (1807).

Luego, la Pandora de Goethe, obsesivo símbolo de la vida como «renuncia impuesta por el Hado», es la versión simbólica barroca que ya manifiesta el total desengaño romántico.

Pero el laberinto simbólico calderoniano es bien concreto, y escénicamente está presente con su valor de gran metáfora: la lucha de dioses y hombres contra sus propias duplicaciones llega a solución a 
través de la intervención de Palas, que encarga a Discordia, disfrazada de villana, entregarle el fatídico don a Pandora.

Se trata de una dorada urna, que, como dice Discordia, tendría que contener los dones de los dioses, o sea la esencia de los cuatro principios elementales del Cosmos; pero como la doncella posee ya uno en su viviente imagen, el principo del fuego, en la urna se hallarían encerrados los tres restantes con la significativa añadidura del eco, probablemetne porque expandiría por todo el mundo la fama y el culto del prodigio, lo cual carga de ulterior valor simbólico la correspondencia entre los versos y la música ambas en eco. De hecho un nuevo retornelo pasa de la hipócrita donadora a todos los aldeanos del Cáucaso en fiesta por el don; y el retornelo escande exactamente los últimos dos versos del baile:
al festejo, al festejo, zagales.
Zagales, venid, venid al festejo
que a la nueva deidead de estos montes
le ofrecen, en fe de ser hija del fuego,
la tierra con flores, el agua con perlas,
el aire con plumas, con salvas el eco ${ }^{19}$.

Según una arcaica tradición, Pandora —asimilada a la diosa de la tierra- era objeto de cultos agrestes de las Antesterias, cuando los Jonios durante tres días y tres noches retenían que las almas de los muertos invadían sus aldeas con el fin de ofrecerles dones, pero causando a la vez pavor. Entonces se abandonaban a la bebida hasta los límites de la orgía dionísica y se espitaban las tinajas del vino nuevo. Esta parte de la fiesta se llamaba Pithoigia — de pithos, urna, tinaja, orza-, y aclara la conexión entre la diosa y su urna que se convertirá en su símbolo.Cuando los ritos de las Antesterias llegan a las ciudades, «Basilissa» la mujer del Arconte-Rey va como esposa en procesión ditirámbica — procesión, pues, dialogada, danzada y cantadaa un simulacro de Dioniso, representando el atributo femenino del ambiguo dios.

Así pues el significado de la personificación de Pandora, como «omnium munus", se aclara en el marco de un rito dionisíaco de propicia-

\footnotetext{
${ }^{19}$ Calderón de la Barca, La estatua de Prometeo, p. 2084.
} 
ción, en las raíces del teatro y de la representación; rito que aúna el drama de la muerte y de la regeneración, así de la naturaleza, como de la actividad humana.

De estos valores - superación de la muerte, regeneración y propiciación de la naturaleza, fomento de todas las artes y desarrollo de las técnicas racionales (las Ciencias) - se apoderó, con objetivos dinásticos y celebrativos, la edad barroca. Ésta, heredando el renacentista «retorno al paganismo", lo hace propio hasta utilizar toda la renovada exégésis mitológica para las exigencias carismáticas y chamánicas de los nuevos monarcas absolutos ${ }^{20}$. Sobre todo esto se fundan las motivaciones profundas de la fiesta barroca; ésta estalla en la puesta en escena calderoniana - donde los zagales son obviamente los mismos cortesanos- con la máxima entropía que sincretiza significados arcaicos y nuevos.

Se desencadena pues la fiesta del espitado de la tinaja, la pithoigía, en torno al simulacro viviente que es la "hija del fuego", por el hecho de haber recibido la vida gracias al apolíneo rayo que Prometeo, en el momento de su prodigiosa animación, le había puesto en la mano derecha.

Por lo tanto ahora la imagen ya viva viviente posee dos atributos, el rayo de fuego y la urna dorada, exactamente mientras se encuentra en el centro de la fiesta ritual.

Pero, ¿qué encierra en realidad esa urna que define al viviente icono? Nos hallamos ante una ulterior duplicación, ahora entre la mujer y la urna que está en su poder y que la simboliza. En el «motivo de los tres cofres» Freud ${ }^{21}$ muestra que el vínculo entre la mujer y el misterioso contenido de una urna - que puede ser una tinaja, un barril, una urna, una cajita, según las versiones que acompañan todas las representaciones de Pandora- se propone con increíble frecuencia en el mito, en las fábulas, en literatura, en las artes figurativas y en todas las formas de teatro y de representación.

La urna siempre asume el enigma de lo femenino, o sea el presidir el ciclo de la generación y de la muerte, cuanto basta para explicar la explosión de la Pithoigía propiciatoria en torno al simulacro de Pandora con su urna. Aquí, además, la urna es de oro, símbolo del sol

${ }^{20}$ Ver Neumeister, 2000, pp. 279-306.

${ }^{21}$ Freud, 1967. 
y del principio vital. Pero en su interior, en lugar de los dones prometidos, encierra, como veremos, una tétrica bruma, símbolo de la sepultura y de la muerte. Así pues, Pandora, simulacro ceniciento hecho con una mezcla de tierra y agua, se define trámite su atributo contemporáneamente como la seductora y amada regeneradora y como la «palida primera y última mujer».

Cuando Pandora, animada por el deseo de repartir con todos los humanos en fiesta los magníficos dones de los dioses, destapa la urna, un estallido de humo y un terremoto oscurecen de repente la escena con un auténtico golpe teatral; quizás desde el punto de vista escenográfico y luminotécnico el más asombroso entre los muchos que jalonan la fiesta; la aparición de la estatua en el fondo de la caverna, la revelación de Minerva, que se libra del aspecto de fiera, el carro en llamas de Apolo, la reanimación de la doncella, el triunfo final bajo la égida de Apolo.

Pero de la urna calderoniana de Pandora no salen vicios, sino tribulaciones no personificadas, como total cataclisma de la humanidad y, puesto que la divina doncella simboliza las Artes y las Ciencias, como el recipiente que la duplica, puede deducirse un presagio de notable modernidad: de Artes y Ciencias la humanidad puede hasta perecer, cuando éstas no obedezcan a la pauta de Minerva, o sea de la Razón, y cuando no vayan de acuerdo con los principios naturales de vitalidad y regeneración fecunda representados por los apolíneos rayos del sol.Y, naturalmente, se trata de una preocupación doctrinaria y de una invitación al «Buen Gobierno».

En efecto, el mundo parece hundirse en el Caos: es la lucha de todos contra todos, mientras el bello simulacro viviente intenta seguir la vía de la fuga. La sigue Epimeteo, loco de amor, al cual — según topos barroco del repentino enamoramiento a través de la vista lancinante - le basta ver la estatua para quedar esclavizado, tanto que confiesa: «Pues desde el instante que / vi maravilla tan rara / idolatré su hermosura». Y esto también es de adjudicar a ese poder del icono sobre el que nos hemos detenido. Ahora, que la estatua se ha animado y se le escapa, la desesperación le conduce a la locura.

A su vez Prometeo, horrorizado, huye lejos de su criatura, si bien ésta lo ame devotamente. En tanto la guerra fratricida es sin cuartel, mientras Discordia proclama la condena suprema para los dos reyes: el suplicio de Prometeo y la hoguera, destructora de toda belleza para 
el divino simulacro (exactamente como harían los Iconoclastas, o los modernos reformistas antitridentinos perseguidores de las "vanidades»).

Sobre el mundo resuena ahora un lúgubre retornelo repetido en música por Prometeo y Pandora: «Ahi de quien vio / el bien convertido en mal, y / el mal en peor» ${ }^{22}$.

Cuando todo parece perdido, la intervención de Apolo, convencido por Minerva, no sólo absuelve a los dos reyes, sino que explica que han actuado persiguiendo el bien. Alrededor de las bodas de Pandora y Prometeo, oficiadas por el dios del sol, reexplota la fiesta final, mientras el retornelo que todos bailan y cantan se ha convertido en su opuesto «Felice quien vio / el mal convertido en bien / y el bien en mejor ${ }^{23}$.

Se ha realizado así, bajo la égida de Apolo, la unión entre Prometeo y Pandora, entre la mente humana sabia, creativa y valiente y el viviente simulacro que representa las bellas formas intelectivas de todas las Artes y de todas las Ciencias, el paso de las obras terrenas a la forma sublime que las trasciende: el destino de la humanidad está ahora asegurado, bajo el signo de Urano que retorna.

22 Calderón de la Barca, La estatua de Prometeo, p. 2096.

${ }^{23}$ Calderón de la Barca, La estatua de Prometeo, pp. 2096-2097. 


\section{BiBLIOGRAFÍA}

Amadei-Pulice, M. A., «El stile rappresentativo en la commedia de teatro de Calderón", en Approches of the theatre of Calderón Comedia», ed. M. McGaha, New York / London, Lanham, 1982, pp. 215-230.

Calderón de la Barca, P., Obras Completas. Dramas, I, ed. Á.Valbuena Briones, Madrid, Aguilar, 1966.

- La estatua de Prometeo, ed., M. Greer y L. K. Stein, Kassel, Reichenberger, 1986.

Cancelliere, E., «Campo dello sguardo e della parola in una commedia di Calderón», en Semiotica della rappresentazione, ed. R. Tomasino, Palermo, Flaccovio, 1984, pp. 295-302.

Di Giacomo, G., «Il Secondo Concilio di Nicea e il problema dell'immagine», en Nicea e la civiltà dell'immagine, Aesthetica Preprint, ed. L. Russo, 52, Aprile 1998, pp. 71-86.

Freud. S., Il motivo dei tre scrigni, trad. it., G. Lozza, Torino, Bollati Boringhieri, 1967.

Gambino, R., «L'icona e la sua natura», Pan, Studi del Dipartimento di Civiltà Euro-Mediterranee e di Studi Classici, Cristiani, Bizantini, Medievali, Umanistici, 24, 2008, pp. 127-140.

Neumeister, S., Mito clásico y ostentación. Los dramas mitológicos de Calderón, Kassel, Reichenberger, 2000.

Panofsky, D. y E., Il vaso di Pandora, Torino, Einaudi, 1992.

Platone, Timeo, trad. G. Lozza, Milano, Biblioteca Universale Rizzoli, 1994.

SAge, J. W., «Textos y realización de La estatua de Prometeo y otros dramas musicales de Calderón», en Hacia Calderón. Segundo Coloquio Anglogermano, ed. H. Flasche, Berlin, W. de Gruyter, 1970, pp. 37-52. 
